\title{
The Security and Management of Computer Network Database in Coal Quality Detection
}

\author{
Jianhua SHI ${ }^{1,}$, Jinhong $\mathrm{SUN}^{2}$ \\ ${ }^{1}$ Guizhou Agency of Quality Supervision and Inspection of Coal Product,Liupanshui city \\ 553001, China \\ ashijianhua@163.com
}

Keywords: Computer Network Database; Database Security; Coal Quality Detection

\begin{abstract}
This paper research the results of quality management information system at home and abroad, through the analysis of the domestic coal enterprises coal quality management links and management information system development present situation and existing problems, combining with related theory and system development method of management information system, and according to the coal mining enterprises of computer network security and management, analysis and design of database, and the implementation steps and the implementation of the coal quality management information system of the problem are given their own countermeasure and the suggestion, try to solve demand for management information system of coal enterprise management level, thus improve the coal quality management level and economic benefit of coal enterprise.
\end{abstract}

\section{Introduction}

With the improvement of China's coal mining mechanization degree and the increase of mining depth, coal quality is on the decline as a whole. At the same time, the user of coal product utilization way more and more widely, use more and more diversified, more and higher to the requirement of coal quality. In coal quality issue, therefore, countless contradictions increasingly acute, the gap of supply and demand more hasten is increasing. To solve this problem, need to increase coal blending, washing ability and strengthen coal quality management level [1]. Coal enterprise is typical flow type enterprise, coal mining, processing and marketing links all have different degrees of influence on coal quality, together with the market situation is fast changing, coal production to adapt to the market, prevent quality deficiency or excess, this will make the enterprise production and operation management of information technology, the dependence of the standardization management enhancement, coal quality testing of the computer network database security and management become coal enterprises to realize an important content of modern production and meet the needs of the market. Several shortcomings existing commonly in coal quality management information system in our country today function and the problem of poor universality, to strengthen the security of network database and management of the research has practical significance [2].

In order to adapt to the demand for the development of information age, the safety of the coal quality testing of computer network database technology system optimization is very necessary, in order to improve the coal quality testing the security of network database, in order to better adapt to the demand of modern network information system construction [3]. In this paper, through the introduction of the application of network database security technology present situation and existential threat, and put forward the optimization tactics of the network database security technology. This paper for the adjustment and reconstruction of organization structure, management processes for the design of the coal quality information system, database based on computer network security and management as the key point, in detail the design of the subsystem and its application effect are introduced, and the coal quality management information system for the construction of the coal enterprises have a certain guiding value. 


\section{Computer network database security situation}

The computer network is an open network environment, therefore, the network database data is easily tampered with, illegal access to invade, and the phenomenon such as data loss is inevitable. In network database, there are a lot of documents, sensitive information and confidential data, etc., is the need to be well protected, so under the condition of the computer network database with security threats, and to protect, is urgent to avoid being threatened [4-5]. Specific security threat has the following several aspects:

Connect database downloads. Most of the users in the file, choose to take ASP to the preparation of the connection file. The code in this statement is correct, the database name of insurance work is also safe, and download the user to the database in the database will not be able to conduct destructive behavior. However, in the presence of the download user use of blasting tools, if use blasting tools for database condition can be precise positioning, crack the code above is easy, and the success rate is high. After download user in the database for download, using IE tools can easily get the user name and password.

SQL injection. Most Internet devices are in the use of the WEB server, the server setup has the backing of the solid firewall, basically to open port 80, and it is harder to illegal invasion when users enter the port. So, this particular port has become a hacker attacks the invasion of the goal, solution was injected into SQL. Software developers to write the program operation, in terms of user input data is correct will exist certain negligence, there are some loopholes, then to the application program in the process of users has brought threat. To port 80, SQL injection is in the client is using the input code, based on the processing of application and the server itself, found in the port to data process. Similar with access to the web page, the firewall will be no clear before inject SQL prompt, equivalent to not work, can lead to security threats are not network database management in a timely manner, found that have serious consequences.

\section{Security problem analysis of computer network database for coal quality testing}

Coal quality inspection computer network database to coal as the main business, in charge of coal quality analysis of coal samples, coal and rock, water and so on various aspects of the testing task. As the coal market constantly open up, users put forward higher requirements about the quality of the coal, coal quality testing is more and more shows its importance. Coal quality testing of computer network database is the window of the foreign enterprises, it carries the full analysis of coal and coal quality of scientific research work, it shall issue a testing data level height will directly affect the enterprise prestige, therefore, the coal companies to strengthen coal quality detection of database security and computer network management.

In order to effectively solve the coal quality testing of the computer network database security and management issues, the analysis of coal quality testing process is very necessary. Coal quality testing process is based on send the coal sample and sign an agreement to the coal quality report quoted the process operation. The process is shown in figure 1.

First by the inspection unit (each geological team, the coal enterprise, etc.) from coal samples, the laboratory business on the basic information of the coal sample, insert a test project and so on, and generate the entrust agreement; Registration is completed, automatically generated by the system task assignment sheet, coal sample testing task allocation to each lab; Experimenter get coal sample, according to task list and tested. The experimental raw data without paper records, directly by the experimenter input computer, system to automatic processing of experimental data, the repeatability and reproducibility of explicit analysis according to the experiment, according to the coal quality index of inner relationship between rational analyses. All the experimental project is completed, right can be automatically generated by the system of coal quality test report, after review, agree with the report quoted, can printout of coal quality report, submitted to the detection unit. 


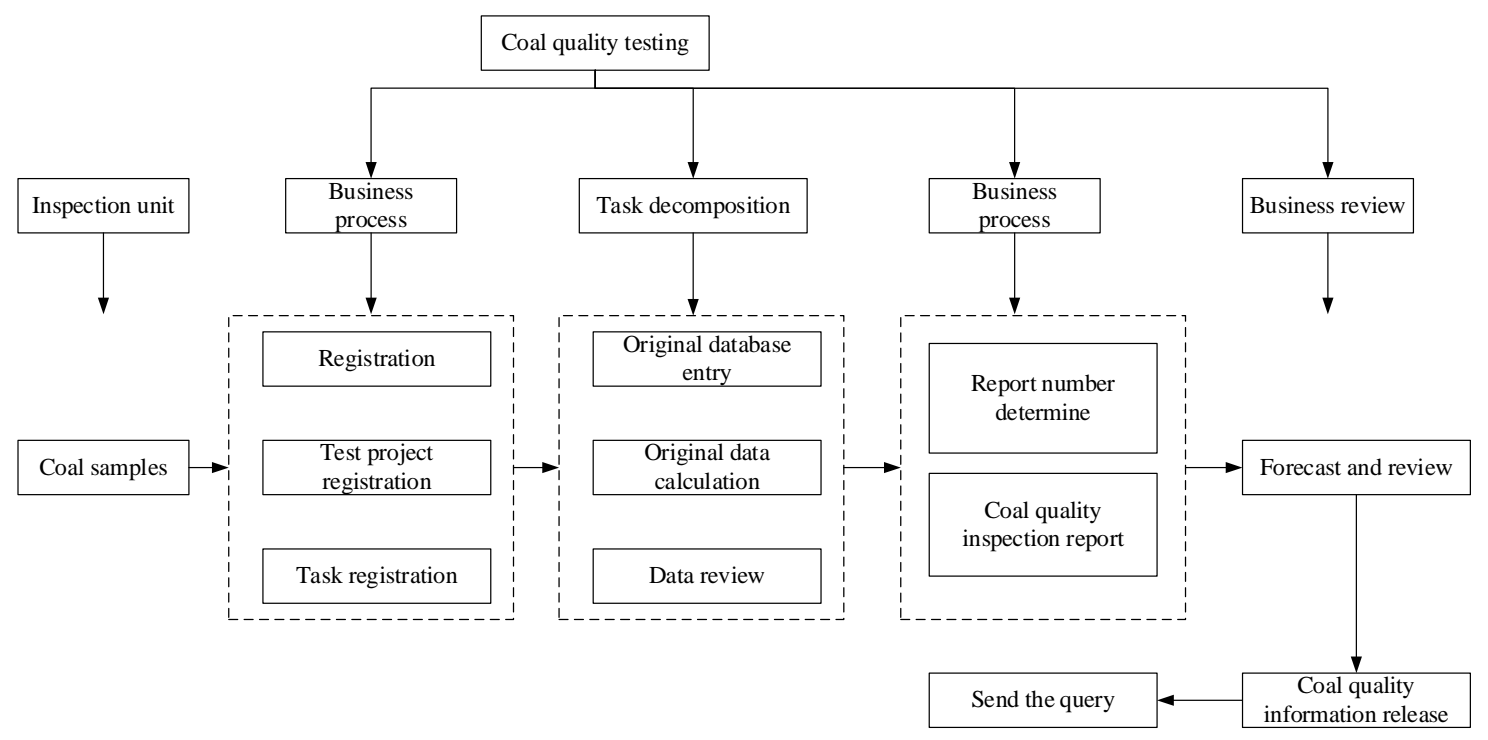

Figure 1.The process of coal quality testing

\section{The safety management of computer network database for the coal quality testing}

In coal quality testing of computer network security management of database, data is the foundation of all operations, therefore, the smooth general characteristic of data stream is successful computer network database security management in coal quality detection of the key factors. The smooth general characteristic also appears especially important, of the data process. In this paper, based on the data flow in coal quality testing database for computer network security management. For the safety of the coal quality testing of computer network database management framework is shown in figure 2 .

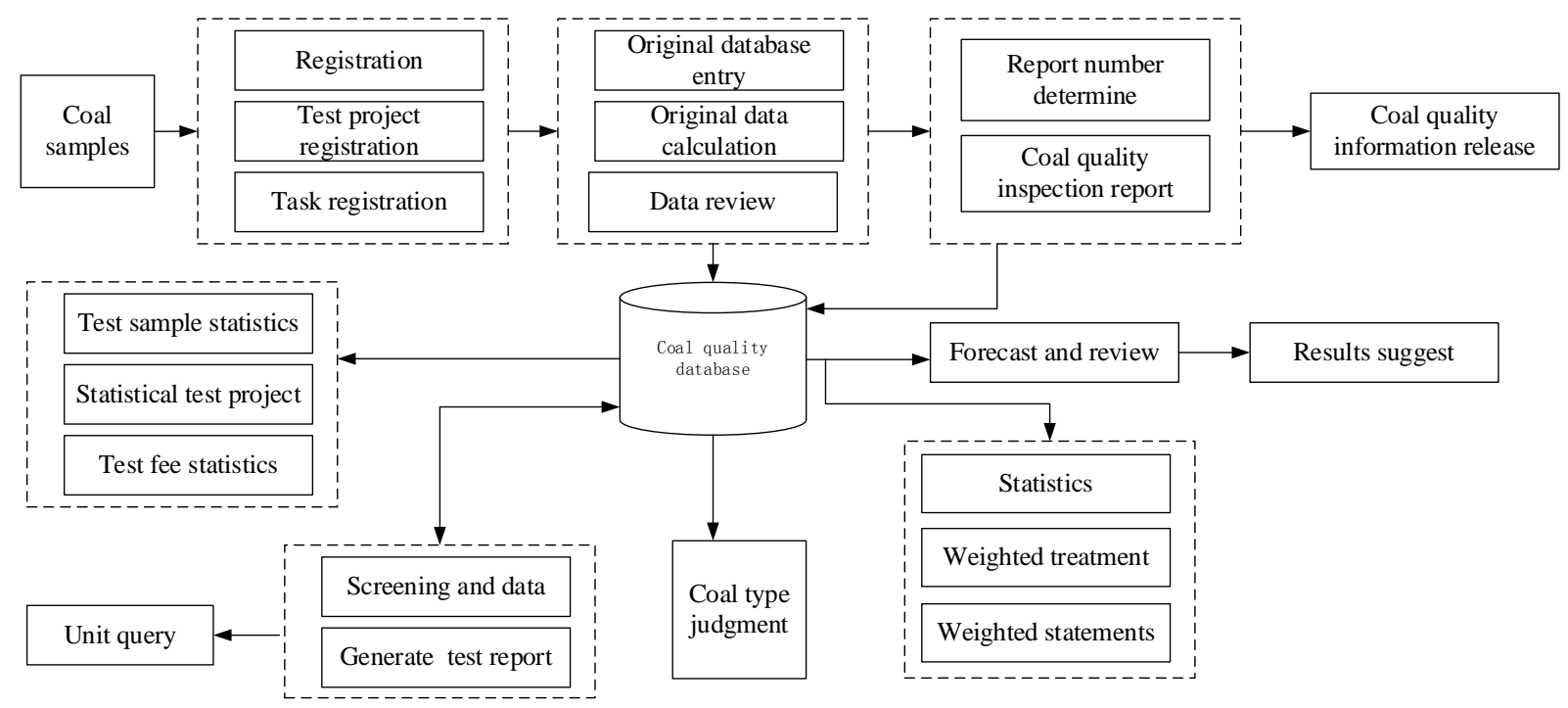

Figure 1. The safety management of computer network database for the coal quality testing

Coal quality testing process, data flow based on coal sample testing information as the main line, the basic information of the coal sample, the test data, statistics, etc. All the coal quality database. Sent test of coal sample inspection unit, the business office to register the coal sample, the producing area of coal sample, ore, Wells and other information in the database, ready to generate reports and provide information of data classification and processing. At the same time, test project information database, and to generate task list. Test data processing module is made up of the operator to the original data entry, will be the correct coal quality data in the database, the module design of large amount of data, source distribution is wide, is the key of the database established. 
Coal quality report module according to generate a report condition, bring up the test data from the database, and thus for processing, the processed data through the forecast and review, judge in the range of error, will review the information in the database, the system analyzed according to the coal quality data in the database, and the statistical results into the database. At the same time, the data is available for the coal handing judgment and geological weighted average processing. Screening fugitive dust is a separate module to development, its data process is relatively simple.

\section{Conclusion}

With the continuous development of society and the advance of computer technology, computer network has been widely used in coal quality testing. Among them, the computer technology is in the process of application of database through the network to realize data storage and management, but due to the developmental characteristics of the network, computer network database under the influence of external factors in the application, it will direct impact on the entire computer network safety. Coal quality testing of computer network oriented database data is stored in a large amount of information, in case of a variety of security issues, will lead to a large number of information data, will lead to serious consequences. At present, the coal quality testing has been focus on computer database security problem, so to strengthen the study of coal quality testing of computer network database is very necessary, and according to its threat to take targeted and effective optimization strategy, to ensure the security of network database is of great importance.

\section{Reference}

[1] WANG X, QU J, HUANG J: Netinfo Security, 2012, 2: 009.

[2] Aydin M A, Zaim A H, Ceylan K G: Computers \& Electrical Engineering, 2009, 35(3): 517-526.

[3] Kandukuri B R, Paturi V R, Rakshit A: Services Computing, 2009. SCC'09. IEEE International Conference on. IEEE, 2009: 517-520.

[4] Homer J, Ou X: Selected Areas in Communications, IEEE Journal on, 2009, 27(3): 315-322.

[5] Sultan N: International Journal of Information Management, 2010, 30(2): 109-116. 